\title{
Investigating the effect of heterogeneity on infill wells
}

\author{
Mahmood Bagheri ${ }^{1} \cdot$ Mohsen Masihi $^{2}$
}

Received: 19 November 2014/ Accepted: 17 October 2015/Published online: 1 December 2015

(C) The Author(s) 2015. This article is published with open access at Springerlink.com

\begin{abstract}
In recent years, improving oil recovery (IOR) has become an important subject for the petroleum industry. One IOR method is infill drilling, which improves hydrocarbon recovery from virgin zones of the reservoir. Determining the appropriate location for the infill wells is very challenging and greatly depends on different factors such as the reservoir heterogeneity. This study aims to investigate the effect of reservoir heterogeneity on the location of infill well. In order to characterize the effect of heterogeneity on infill well locations, some geostatistical methods, e.g., sequential gaussian simulation, have been applied to generate various heterogeneity models. In particular, different correlation ranges $(R)$ were used to observe the effect of heterogeneity. Results revealed that an increase in correlation ranges will lead to (1) a higher field oil production total, and (2) a faster expansion of the drainage radius which consequently reduced the need for infill wells. The results of this study will help engineers to appropriately design infill drilling schemes.
\end{abstract}

Keywords IOR · Infill wells · Heterogeneity - SGS · Correlation ranges $\cdot$ Drainage radius

Mahmood Bagheri

mbagheri@me.com

Mohsen Masihi

masihi@sharif.edu

1 Department of Petroleum Engineering, Science and Research Branch, Islamic Azad University, Tehran, Iran

2 Department of Chemical and Petroleum Engineering, Sharif University of Technology, Tehran, Iran

\section{Introduction}

Infill drilling technique plays an important role in reservoir development especially in tight reservoirs. Increasing oil price and limitations of new reserves make improving oil recovery methods inevitable. As the recovery ratio is controlled by many complicated factors, such as the level of reservoir heterogeneity, determining the location of infill wells seems to be a very challenging issue (Soto et al. 1999). Hence there is no homogeneous reservoir in reality, and it is widely believed that in heterogeneous reservoirs infill drilling plays an important role (Hou and Zhang 2007; Barber et al. 1983) and improves oil recovery by accelerating productions (Driscoll 1974; Gould and Munoz 1982; Gould and Sarem 1989; Sayyafzadeh and Pourafshari 2010). Moreover, if infill drilling is linked to water flooding, it becomes more effective and economical comparing to chemical injection or tertiary recovery (Holm et al. 1980; French et al. 1991; Thakur and Satter 1998). The existence of different rock types with various thicknesses between two wells in a reservoir may cause a complex flow behavior. One of the applications of infill wells is to reduce the distance between the wells which helps maintain layer continuity and enhances well connectivity (Wu et al. 1989; Malik et al. 1993).

Making a precise decision on the location and number of infill wells is critical to the economics of an infill drilling project. Feasibility of infill drilling potential, especially in marginal fields, must be reliably assessed both technically and economically (Cheng et al. 2008). Therefore, it is highly recommended to conduct a complete reservoir evaluation consisting of geological, geophysical, and petrophysical reservoir analysis and interpretations to determine infill drilling potential in a reservoir. While this is a very accurate method, this approach can be 
Table 1 Known permeability data in the reservoir model

\begin{tabular}{lllllllllll}
\hline Cell location & $(32,47)$ & $(31,26)$ & $(27,90)$ & $(20,12)$ & $(15,86)$ & $(10,32)$ & $(6,2)$ & $(5,30)$ & $(2,80)$ & $(1,5)$ \\
K (md) & 208.812 & 107.974 & 32.9067 & 73.5827 & 262.615 & 198.433 & 176.104 & 91.4402 & 73.5827 & 151.29 \\
Cell location & $(93,55)$ & $(85,47)$ & $(81,31)$ & $(64,44)$ & $(62,95)$ & $(59,29)$ & $(51,1)$ & $(43,22)$ & $(39,79)$ & $(36,67)$ \\
K (md) & 187.548 & 262.615 & 228.224 & 91.4402 & 151.29 & 123.366 & 278.007 & 270.444 & 54.1704 & 151.29 \\
\hline
\end{tabular}

prohibitively time consuming and expensive for hydrocarbon fields.

Methods of investigating infill well potential are divided into two main categories: (1) statistical methods and (2) optimization methods.

\section{Statistical methods}

A statistical view is the first approach in reservoir evaluation. The most common method in statistical approaches is the moving window technique. This method can use a minimum amount of reservoir geological description to determine the infill potential (Fuller et al. 1992). There have been a multitude of empirical and statistical analysis developments in the moving window method (Hudson et al. 2000, 2001). McCain et al. (1993) particularly used the statistical moving window approach to determine infill potential in a complex, low-permeability gas reservoir (McCain et al. 1993). Later, Voneiff and Cipolla (1996) developed the moving window technique and applied it for rapid assessment of infill and recompletion potential in the field (Voneiff and Cipolla 1996).

The other approach to find infill candidate wells is rapid inversion. In this technique, which was introduced and developed by Gao and McVay (2004), reservoir simulation is combined with automatic history matching (Gao and McVay 2004). In rapid inversion, a reservoir simulator serves as the formal method to calculate well production responses from reservoir description data. Then sensitivity coefficients are calculated internally and are used in the estimated permeability field and forward model. Lastly, the expected performances of potential infill wells can be determined (Guan et al. 2005).

\section{Optimization method}

Disseminating the locations of well is one critical issue in exploration and development of oil and gas fields. The process of determining the optimal well location is an optimization problem.
Table 2 Model parameters

\begin{tabular}{ll}
\hline Property & Explanation \\
\hline Number of permeability data points & 20 \\
Reservoir dimensions & $2500 \times 2500 \times 30 \mathrm{ft}$ \\
Number of grids & $100 \times 100 \times 1$ \\
Variogram type & Isotropic spherical \\
Uniform interval & $625 \mathrm{ft}$ \\
Minimum permeability & $0 \mathrm{md}$ \\
Maximum permeability & $300 \mathrm{md}$ \\
Number of simulation runs & 100 times \\
\hline
\end{tabular}

Shook and Mitchell (2009) used time-of-flight to extend the derivation of classical measures of heterogeneity to three-dimensional models. They proposed application of flow-capacity/storage-capacity F- $\emptyset$ diagram, Lorenz coefficient. Moyner et al. (2014) used flow diagnostics for reservoir management. They used Lorenz coefficient as the popular measure of heterogeneity in the context of streamline. Based on their work, the coefficient perfectly correlated with oil recovery predicted by a multiphase flow simulation. Also they used Lorenz coefficient as an objective function for optimization process (Moyner et al. 2014).

Although the Lorenz coefficient correlates well with recovery, it will generally give multiple local minimums and using from global optimization method will be necessary.

Several new methods are suggested by researchers, and only a few studies have presented a careful comparison of their performance with more popular genetic algorithmbased and gradient-based optimization techniques. (Onswnulu and Durlofski 2010; Nasrabadi et al. 2012).

\section{Genetic algorithm}

This method is one of the most popular methods in the well placement optimization. The idea of a genetic algorithm is first introduced by Holland in 1975 (Ariadji et al. 2014).

The genetic algorithm is a stochastic and heuristic search technique (Abukhamsin 2009). A genetic algorithm, 

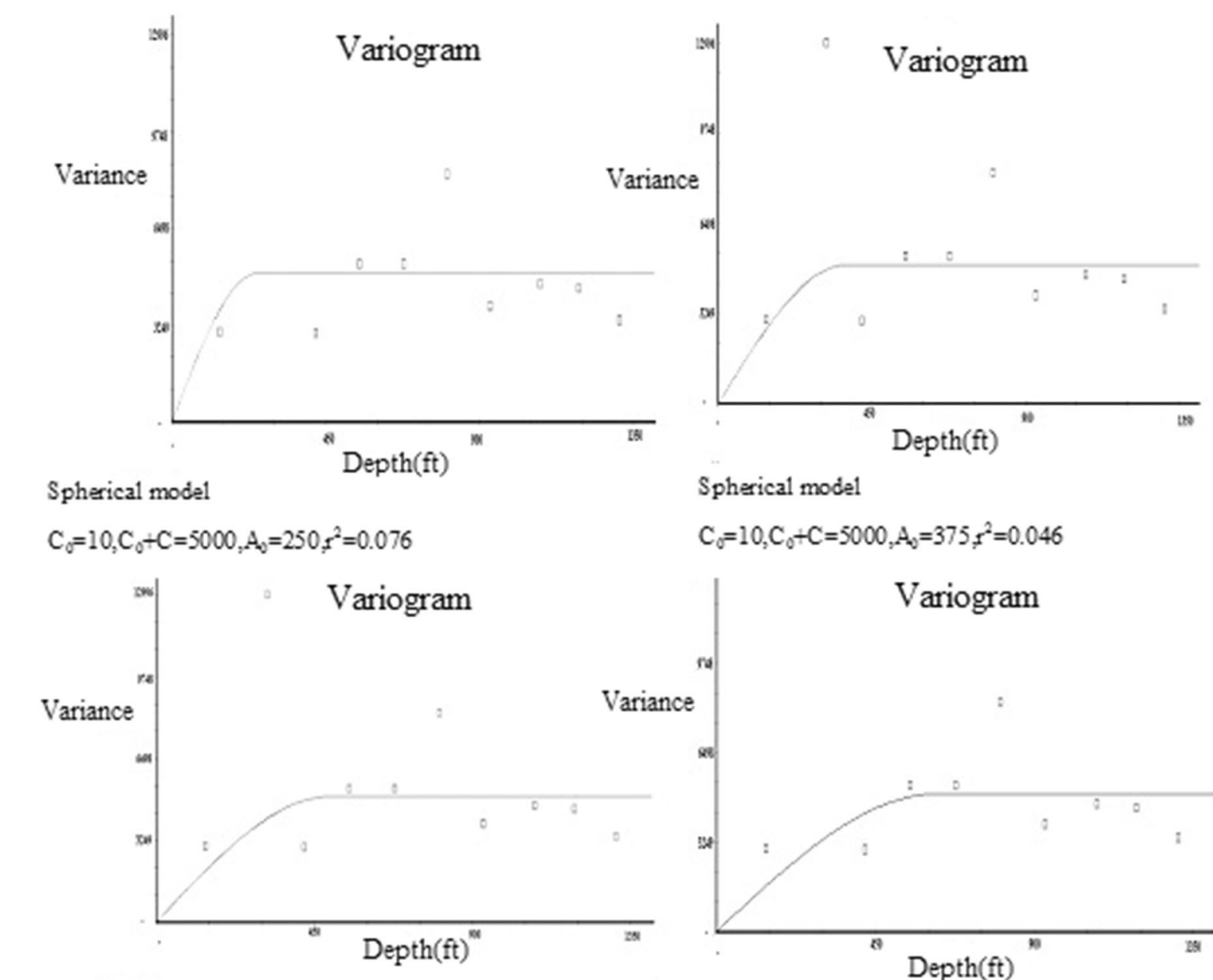

Spherical model

$C_{0}=10, C_{0}+C=5000, A_{0}=500, x^{2}=0.01$

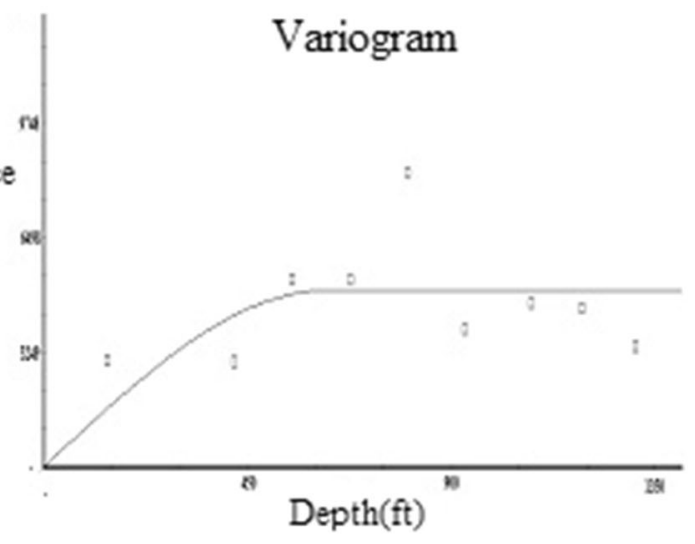

Spherical model

$\mathrm{C}_{0}=10, \mathrm{C}_{0}+\mathrm{C}=5000, \mathrm{~A}_{0}=625, \mathrm{r}^{2}=0.03$

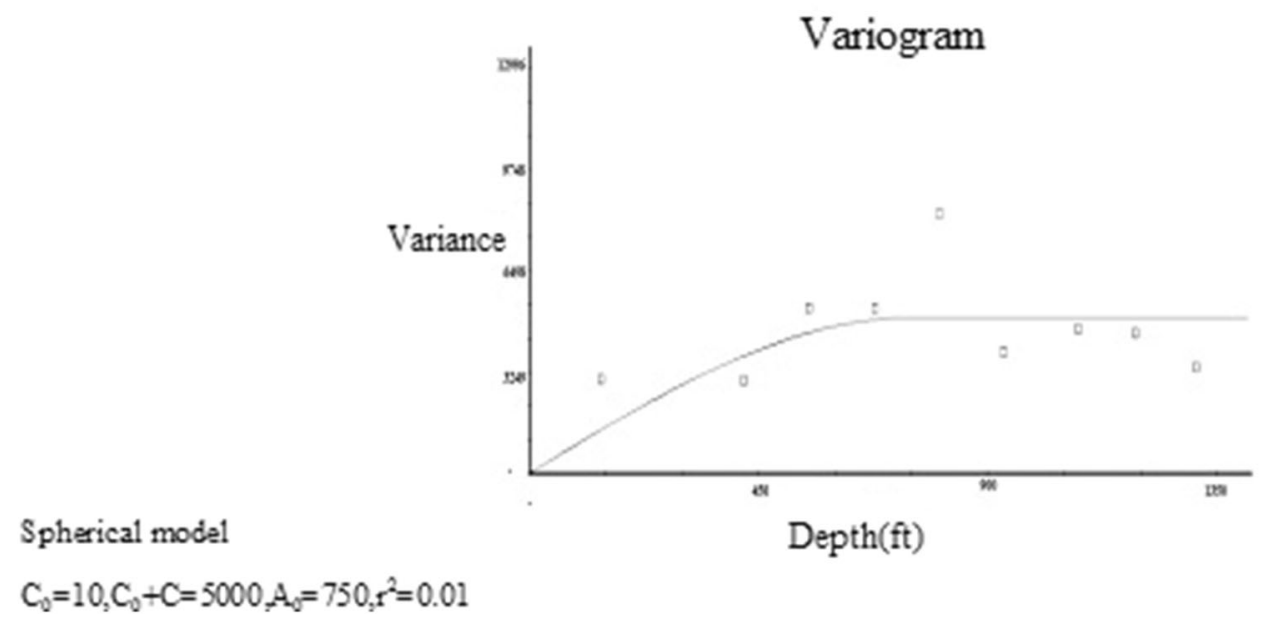

Fig. 1 Variogram models for different realizations 
Table 3 Variogram model parameters

\begin{tabular}{lllll}
\hline No. & Variogram type & Range (ft) & Sill & Nugget \\
\hline 1 & Spherical & 250 & 5000 & 10.0 \\
2 & Spherical & 375 & 5000 & 10.0 \\
3 & Spherical & 500 & 5000 & 10.0 \\
4 & Spherical & 625 & 5000 & 10.0 \\
5 & Spherical & 750 & 5000 & 10.0 \\
\hline
\end{tabular}

in its purest form, will try to replicate the concepts of natural evolution, in a controlled and mathematical environment. In a well placement optimization problem, the different individuals in a generation are replaced with well location data, and their cumulative production or NPV is a measure of their chance of survival (Nasrabadi et al. 2012).

The first step in optimization of well placement by genetic algorithm is to generate an initial population (randomly selected well locations). The next step will be to evaluate each well and rate their individual performance by calling a reservoir objective function.

\section{Gradient method}

Gradient-based method is an important class of optimization methods. This method provides an improved objective function; each iteration results in a better well placement scenario, close to the original selection within a few iterations (Nasrabadi et al. 2012).

As the optimal location for a new well depends on how it is to be operated, Isebor et al. (2014) considered well location and well control optimization problems simultaneously as a joint problem and applied gradient approach in addition to several other methods to solve the optimization problem. They believed that exclusive gradient method may get trapped in relatively poor local optima (Isebor et al. 2014).

Current optimization methods do not include both reliability and efficiency features simultaneously. Although gradient-based methods are very efficient, they are highly dependent on the initial guess and cannot guarantee finding a global optimum. However, more reliable methods, such
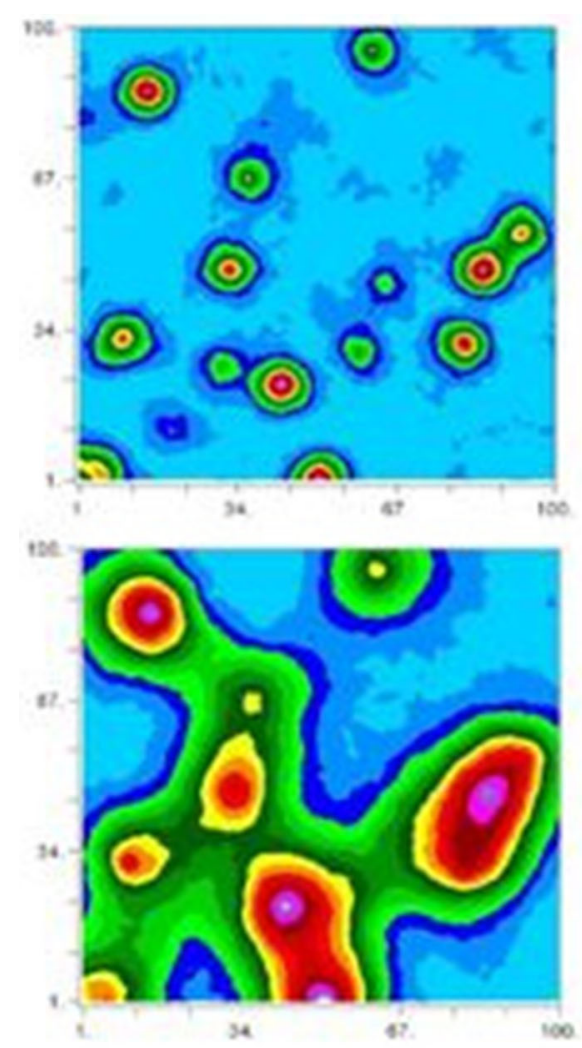
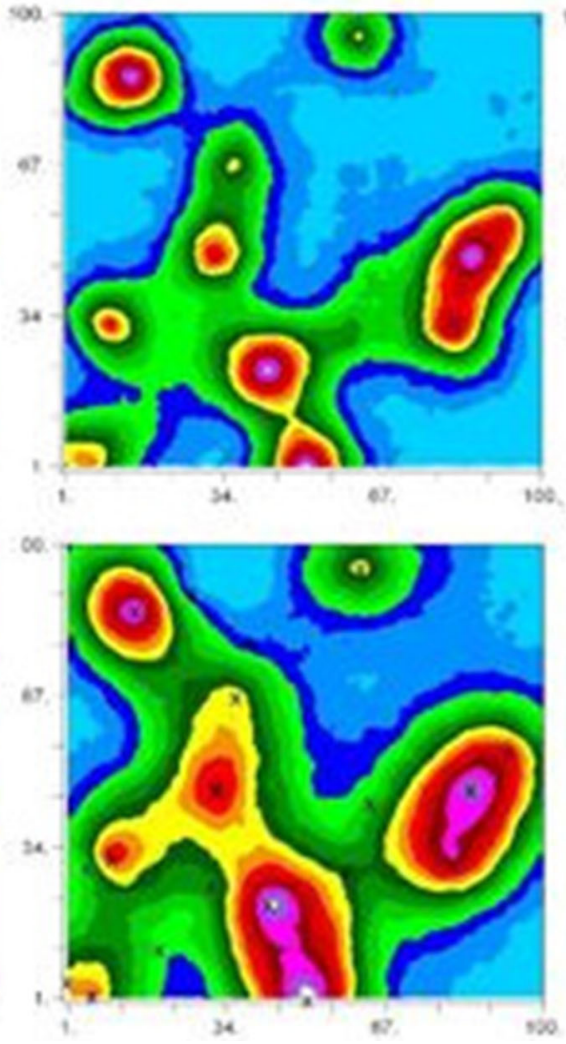

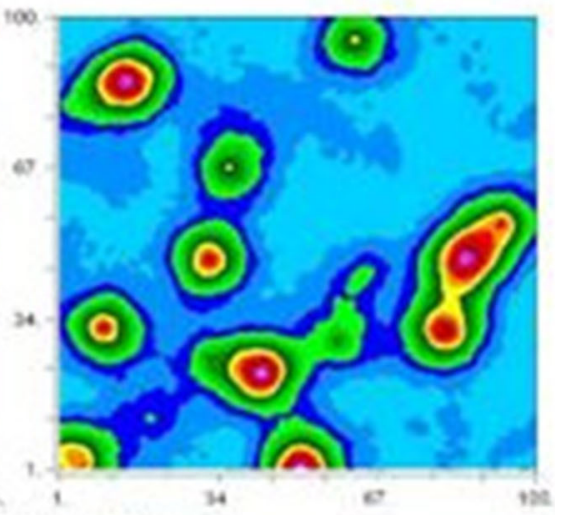

Permeablity

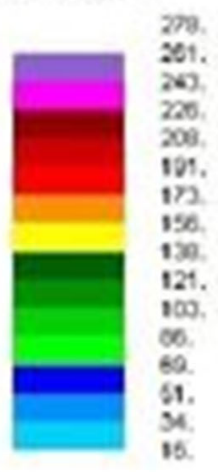

Fig. 2 Permeability model generated using the variogram of Fig. 1 
Fig. 3 5-spot well pattern and the selected infill wells between them
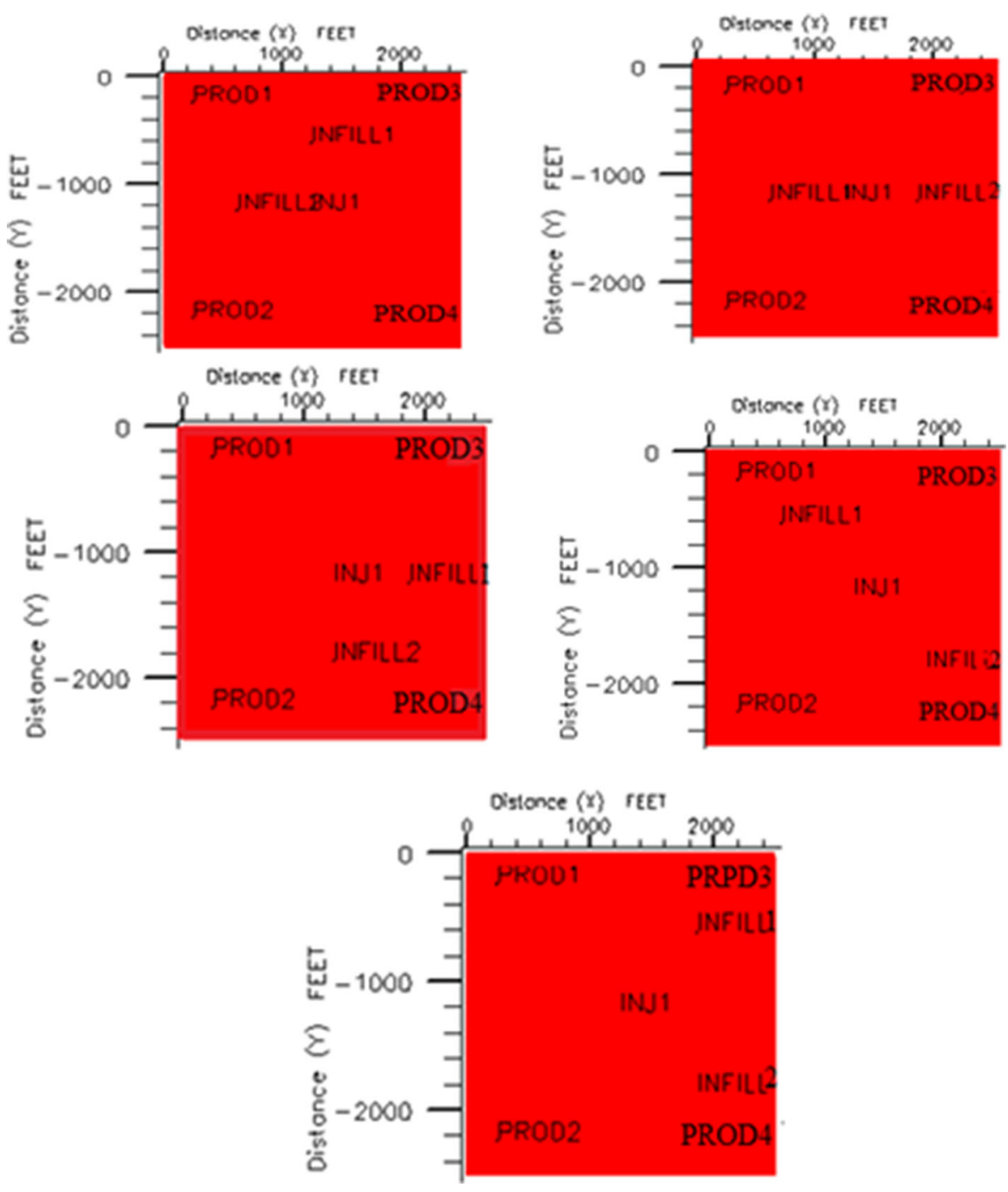

as genetic algorithm, need an excessive number of reservoir simulation which makes their field application very expensive (in terms of required CPU time or computational hardware).

In order to solve such problems, there are new and advanced methods. However, it should not cause neglecting basic methods. Although more advanced optimizationbased techniques have been presented for well placement, this is a basic research attempting to find a relation between correlation lengths in permeable/impermeable region with well spacing within infill drilling decision. We used geostatistical method to investigate the effect of heterogeneity on infill wells.

\section{Model set-up and procedure}

The starting point in system behavior recognition is generating a static reservoir model. Generally, in simulation and modeling, the number of known parameters is less than 

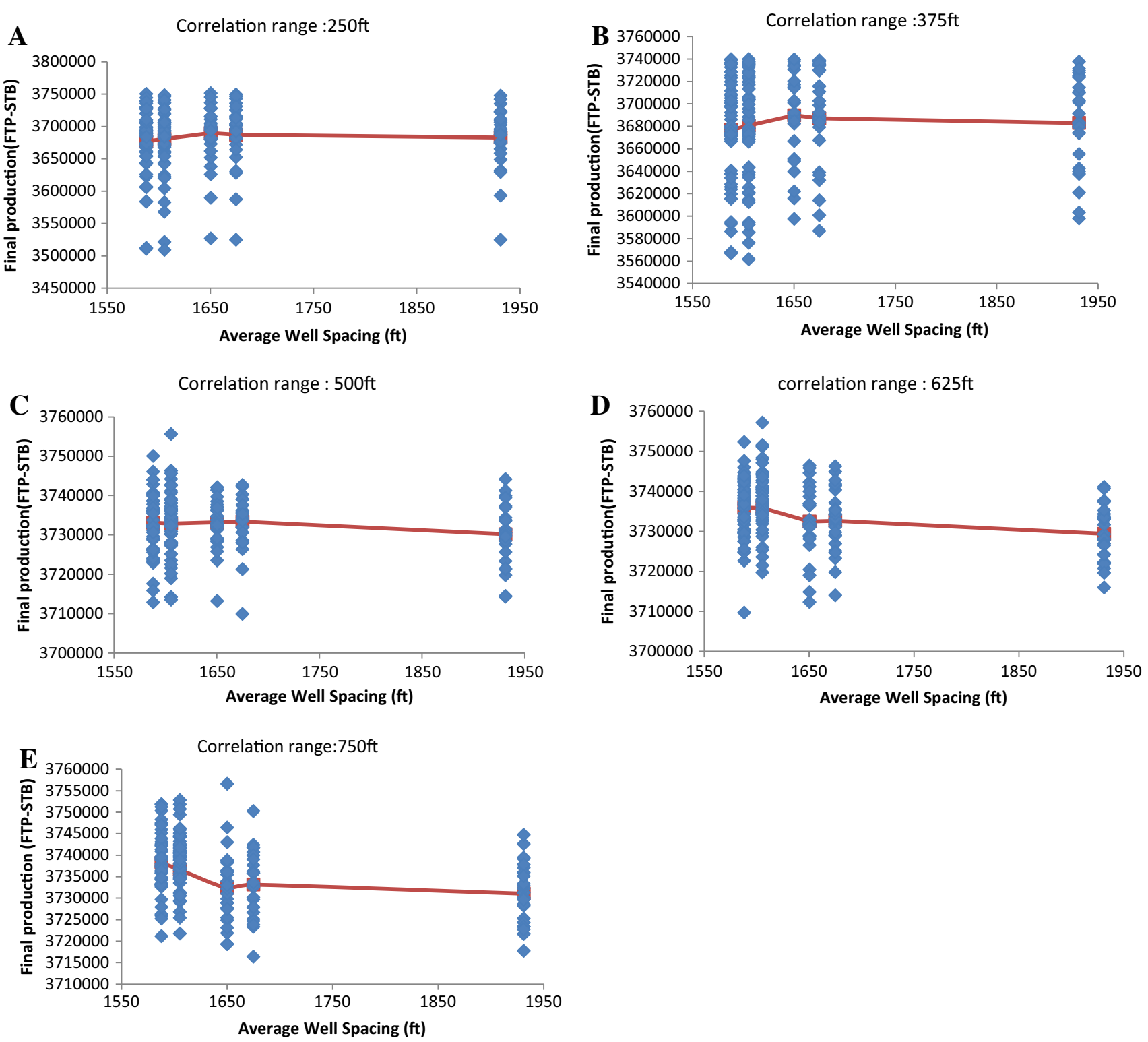

Fig. 4 Final production versus average well spacing for each correlation ranges (from diagram a-e): 250, 375, 500, 625, and 750 (ft)

that of the unknown ones. Therefore, applying a suitable estimation method for solving the problem is essential. In addition to all estimation techniques, simulations based on geostatistical methods, such as Sequential Gaussian simulation (SGS), seem to be very efficient. In the SGS method, different realizations can be produced from a data series with the same probability. This method is an appropriate technique for generating data with constant spatial variability of statistical parameters. In this study, after generating the heterogeneity factors with the SGS method, a 5-spot standard model has been applied for the basic wells' arrangement. Then heterogeneities in five different correlation ranges (drawn from the SGS model results) were applied in the basic model.

In particular, 20 permeability data points were used to generate the permeability model using geostatistical 
Table 4 The reservoir characteristics

\begin{tabular}{lc}
\hline Reservoir characteristics & Explanation \\
\hline Reservoir dimensions & $2500 \times 2500 \times 30 \mathrm{ft}^{3}$ \\
Reservoir depth & $18,000 \mathrm{ft}^{3}$ \\
Grid numbers & $100 \times 100 \times 1$ \\
Grid dimensions & $25 \times 25 \times 30 \mathrm{ft}^{3}$ \\
Porosity & $20 \%$ \\
Reservoir rock type & Sandstone \\
Reservoir rock compressibility & $1.2 \mathrm{E}-6(1 / \mathrm{psi})$ \\
Reference pressure & $4100 \mathrm{psi}$ \\
Initial reservoir pressure & $3000 \mathrm{psi}$ \\
Initial water saturation & $20 \%$ \\
Residual oil saturation & $15 \%$ \\
Oil density & $37.457 \mathrm{lb} / \mathrm{ft}^{3}$ \\
Water density & $62.366 \mathrm{lb} / \mathrm{ft}^{3}$ \\
Oil viscosity & $1.174(\mathrm{Cp})$ \\
Water viscosity & $0.9(\mathrm{Cp})$ \\
\hline
\end{tabular}

Table 5 Well characteristics

\begin{tabular}{lr}
\hline Well characteristics & Explanation \\
\hline Water injection pressure & 3000 psi \\
Production type & Constant rate \\
Production rate & 2000 STB/day \\
Water cut limit & $90 \%$ \\
Simulation start day & 30 Jan 2013 \\
Simulation time & 30 years \\
\hline
\end{tabular}

methods (Table 1). Therefore, in order to show the heterogeneity effect, five different correlation ranges of $250,375,500,625$, and $750 \mathrm{ft}$ were applied in the variogram model construction. By means of SGS, 25 different realizations were produced to calculate the error of each correlation range. However, it should be noted that some assumptions were taken into account before generating the permeability models. For this research, a one-layer reservoir with $2500 \mathrm{ft} \times 2500 \mathrm{ft} \times 30 \mathrm{ft}$ dimensions which consists of $100 \times 100 \times 1$ grids in the $x, y$, and $z$ directions was applied. The reservoir rock type was normal sandstone with a constant porosity of $20 \%$, and the initial pressure of the reservoir rock was 2000 psi (Table 2).

Figure 1 illustrates the applied variograms in the reservoir modeling. The assumptions for the variogram model construction are given in Table 3 .

An example of a permeability map generated using the variogram shown in Fig. 1 is plotted in Fig. 2.

In order to generate the permeability map, a 5-spot pattern is applied as the basic scenario on the reservoir which consists of four production wells and one injection well in the middle of the reservoir. Then, two infill 


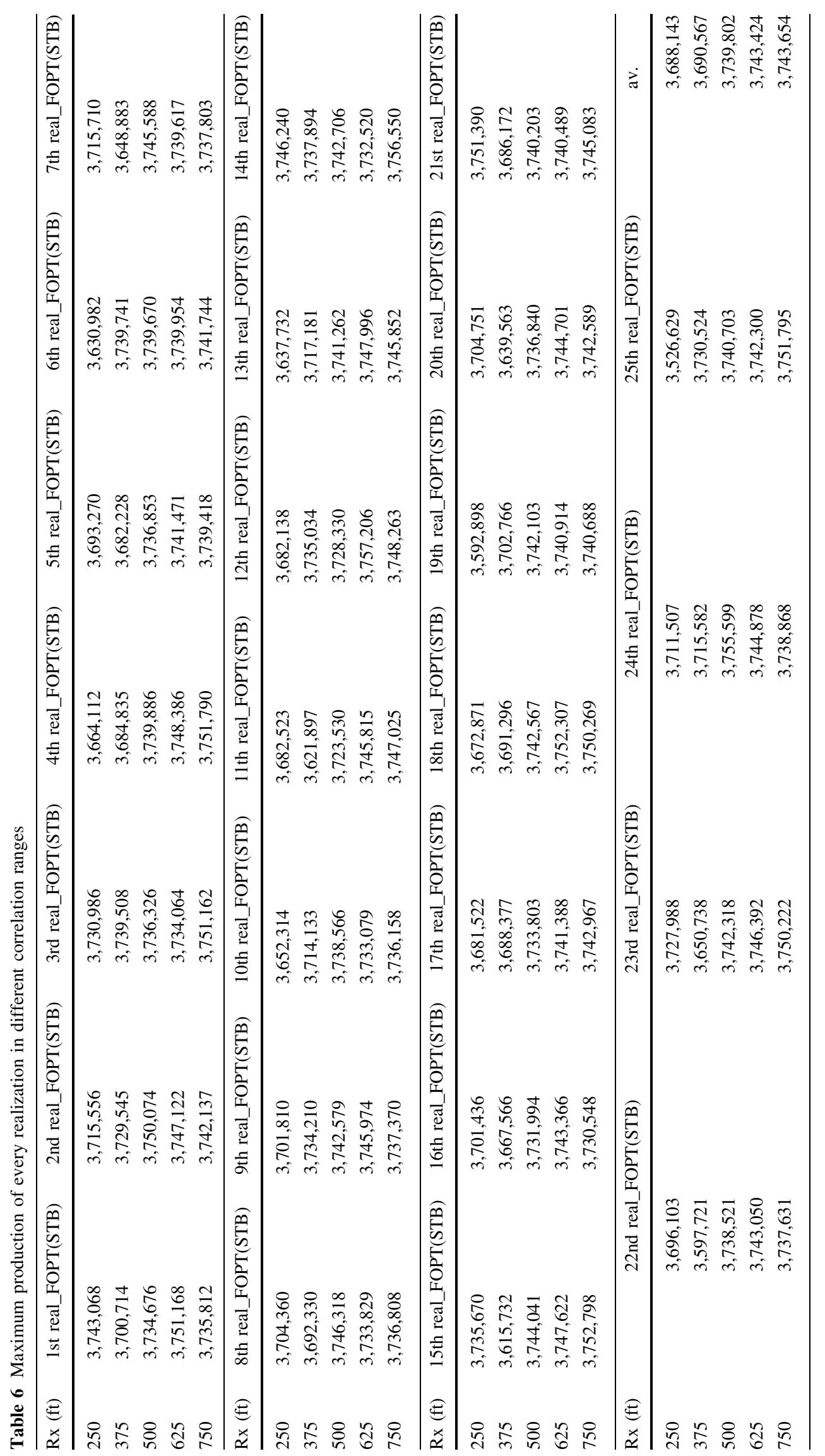




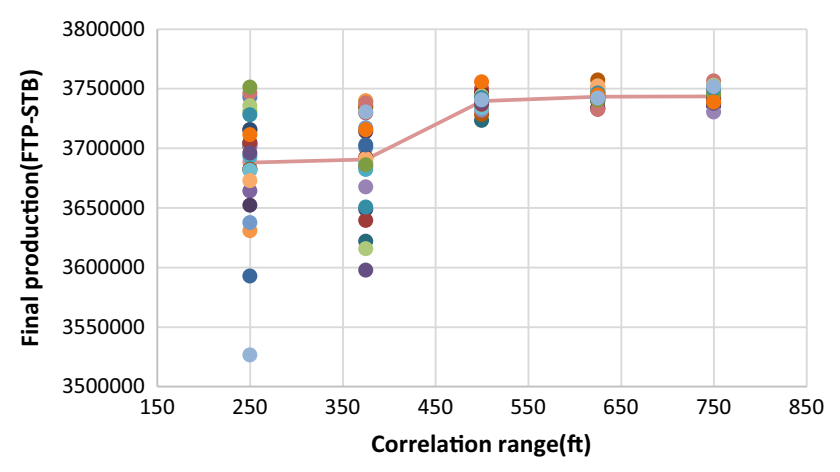

Fig. 5 Final production of reservoir versus correlation range potentials were placed in the basic model at six different locations (Fig. 3). Each production well produces with the constant rate of $2000 \mathrm{bbl}$./day and the injection pressure is 3000 psi. The simulation was applied to this reservoir to predict the reservoir behavior for 40 years of production. Thereafter, 100 realization simulations took place for each well configuration, and the average of these 100 simulations was considered for each correlation range. Finally, total production of each case was compared to the average well spacing for each infill pattern as shown in Fig. 4. Also, characterization of production reservoir mentioned in Tables 4,5 .

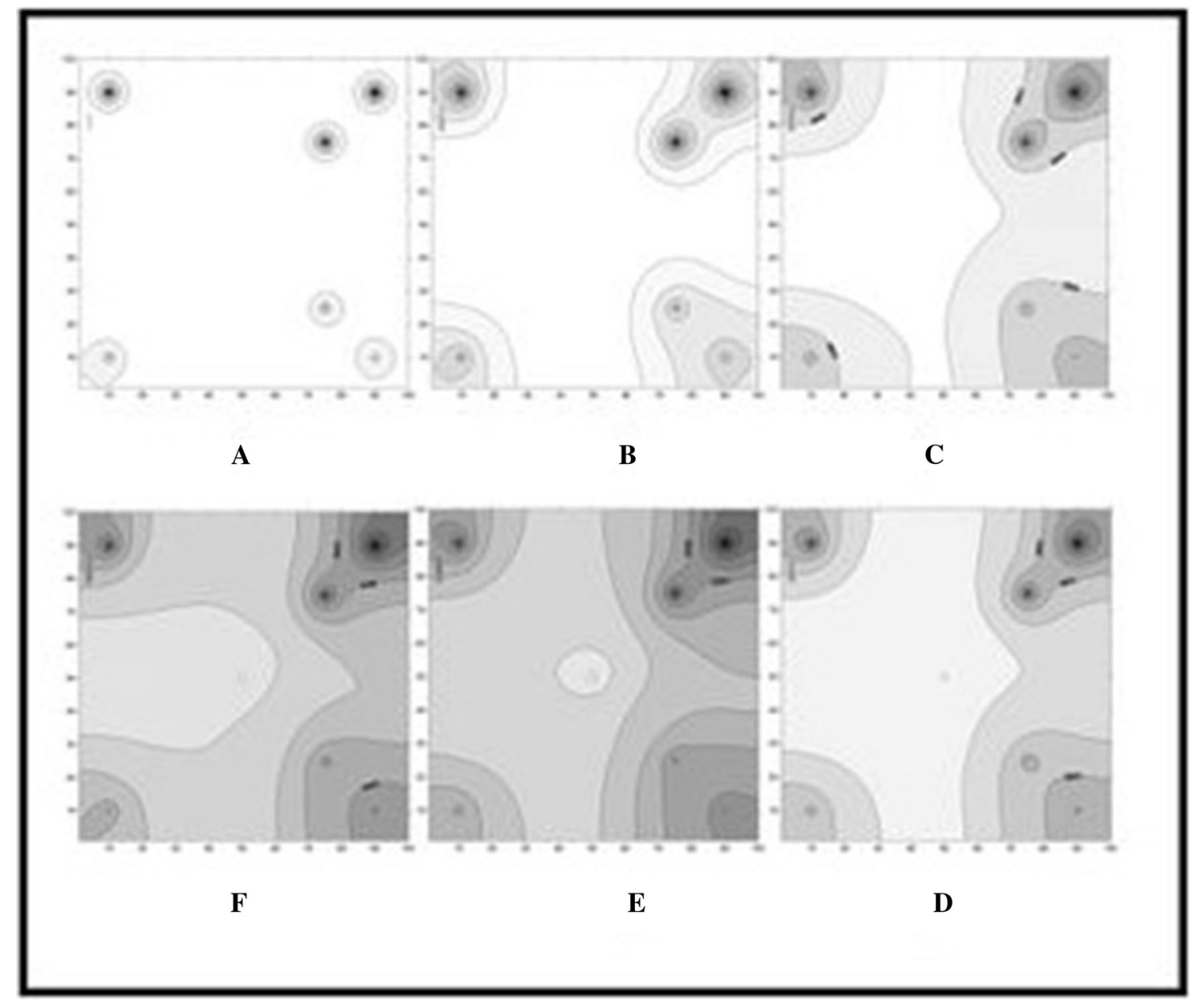

Fig. 6 Drainage radius after the first 10 days for the model (with correlation range of $625 \mathrm{ft}$ ) 


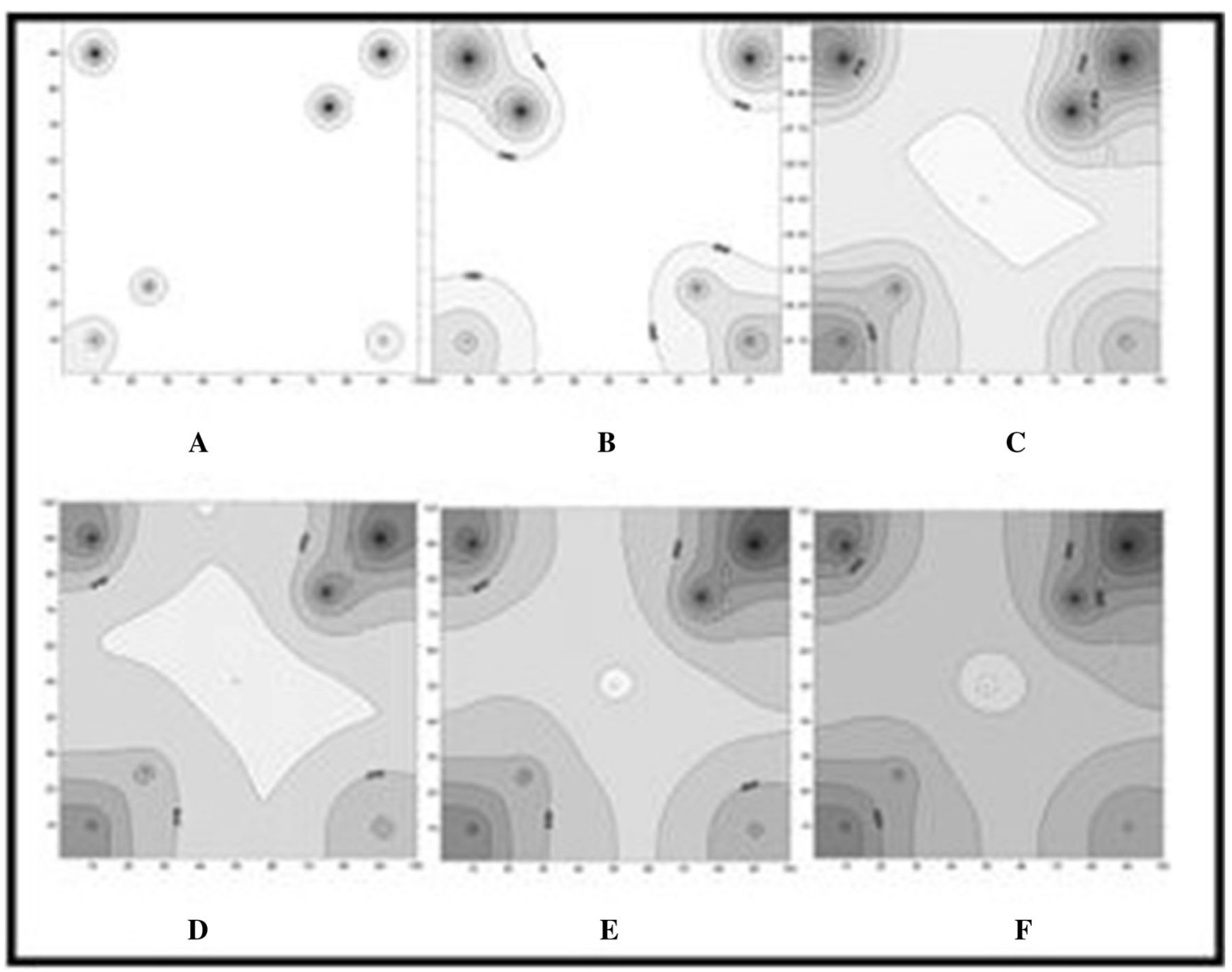

Fig. 7 Drainage radius after the first 10 days for the model (with correlation range of $500 \mathrm{ft}$ )

Table 7 Drainage radius in every correlation range

\begin{tabular}{llllll}
\hline & Rx 250 & Rx 375 & Rx 500 & Rx 625 & Rx 750 \\
\hline Day 1 & 443.807 & 443.425 & 425.268 & 450.115 & 791.284 \\
Day 2 & 705.275 & 715.596 & 721.33 & 1204.13 & 1026.38 \\
Day 4 & 850.057 & 920.298 & 1014.91 & 1390.48 & 1384.75 \\
Day 6 & 951.835 & 1192.66 & 1324.54 & 1390.48 & 1390.48 \\
Day 8 & 1069.38 & 1364.68 & 1376.15 & 1390.48 & 1390.48 \\
Day 10 & 1189.79 & 1384.75 & 1384.75 & 1390.48 & 1390.48 \\
Day 12 & 1227.06 & 1384.75 & 1384.75 & 1390.48 & 1390.48 \\
Day 14 & 1235.67 & 1390.48 & 1390.48 & 1390.48 & 1390.48 \\
Day 16 & 1390.48 & 1390.48 & 1390.48 & \\
Day 18 & 1390.48 & & & 1390.48 \\
\hline
\end{tabular}


Fig. 8 Changes of average drainage radius in different correlation ranges versus time

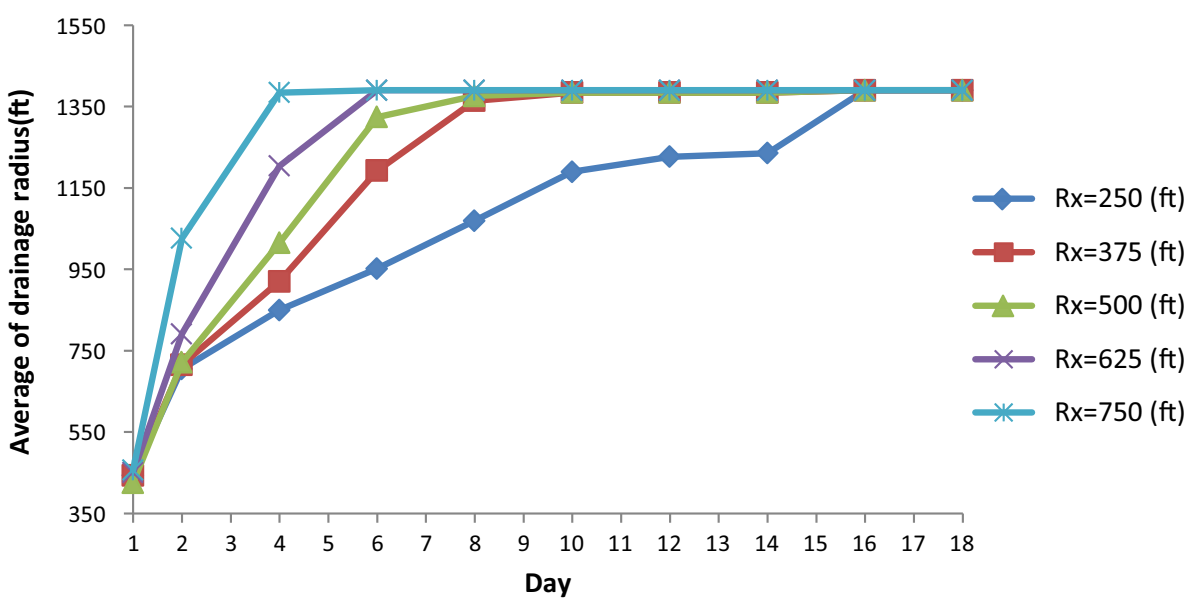

According to Fig. 4, reducing the average well spacing in an infill drilling scenario causes an increase in total production. However, if this average distance becomes less than $1500 \mathrm{ft}$, it will have a reverse effect and the total production will decrease. It should be mentioned that for higher correlation ranges more production in the reservoir occurs with less average well spacing. Moreover, changes in correlation ranges also may affect production values. The maximum production value in each realization and at each correlation range is summarized in Table 6.

Figure 5 illustrates that while the correlation range increases, hydrocarbon production will increase as well. Also, in lower correlation ranges, there are more scattered data than those observed at higher correlation ranges. This may be caused by higher correlation ranges leading to a greater effective radius in the simulation outcomes. Therefore, the reservoir will be more homogeneous, and, as a result, the production rate from the reservoir will increase.

In order to observe the changes in the well drainage radius, the pressures of each cell were calculated, and the isobar surfaces were plotted at different time steps. The graphs reveal that the pressure diminished through the production period (Figs. 6, 7; Table 7).

It can be concluded from the graphs seen in Fig. 8 that it takes more time for the drainage radius to reach its maximum level in lower correlation ranges. This means that by increasing the correlation ranges, the heterogeneous reservoir can be assumed to be a homogeneous one (see Fig. 9).

\section{Conclusions}

In this research, the effect of reservoir heterogeneities generated by geostatistical methods applied to infill drilling scenarios has been discussed. The following can be concluded from this study:

1. Infill drilling is an appropriate method in developing hydrocarbon reservoirs and producing more oils.

2. Increasing the correlation range may cause an increase in the production of the reservoir. The production increased almost 59-61\% in the first 10 years and $11-15 \%$ at the end of the simulation. In addition, the maximum drainage radius increased as well.

3. In infill drilling, reducing the average distance between wells to a certain limit resulted in an increase in the total production rate of the reservoir, but while the average distance between wells became less than $1500 \mathrm{ft}$, the final production decreased. 
Fig. 9 Final oil saturation distribution after 40 years (end of simulation) for each correlation range
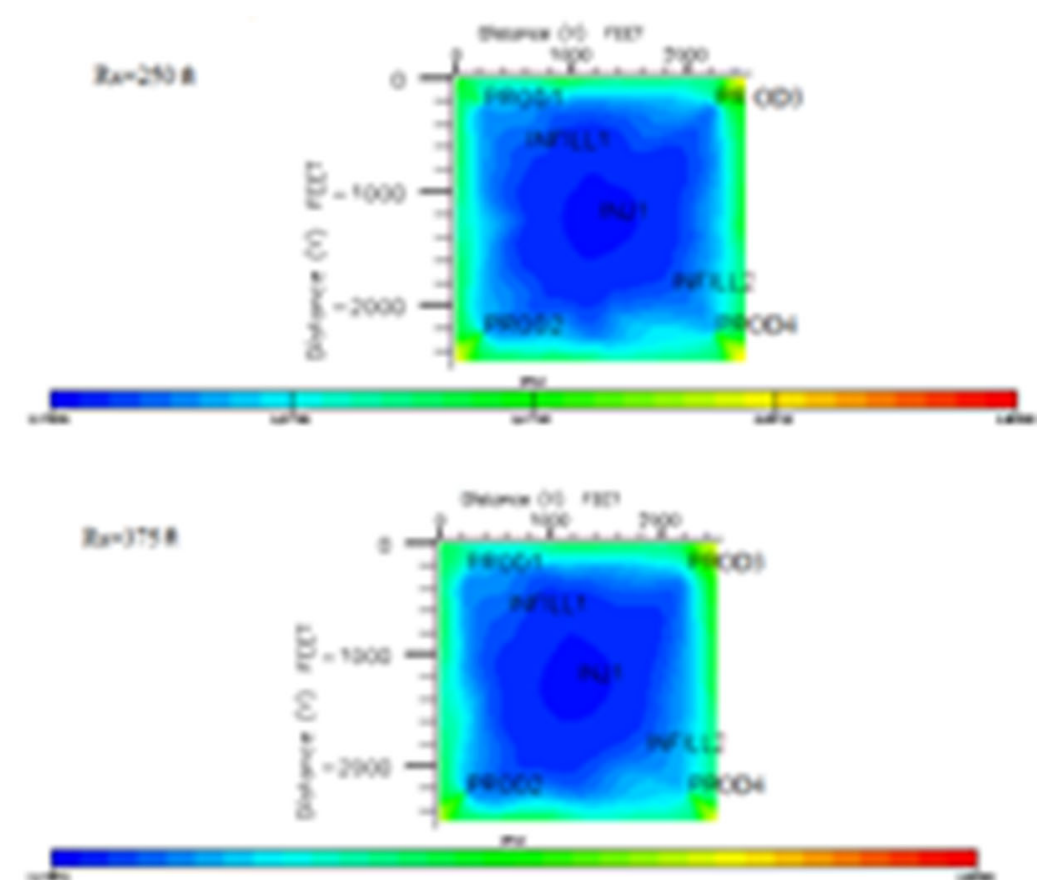

Detos
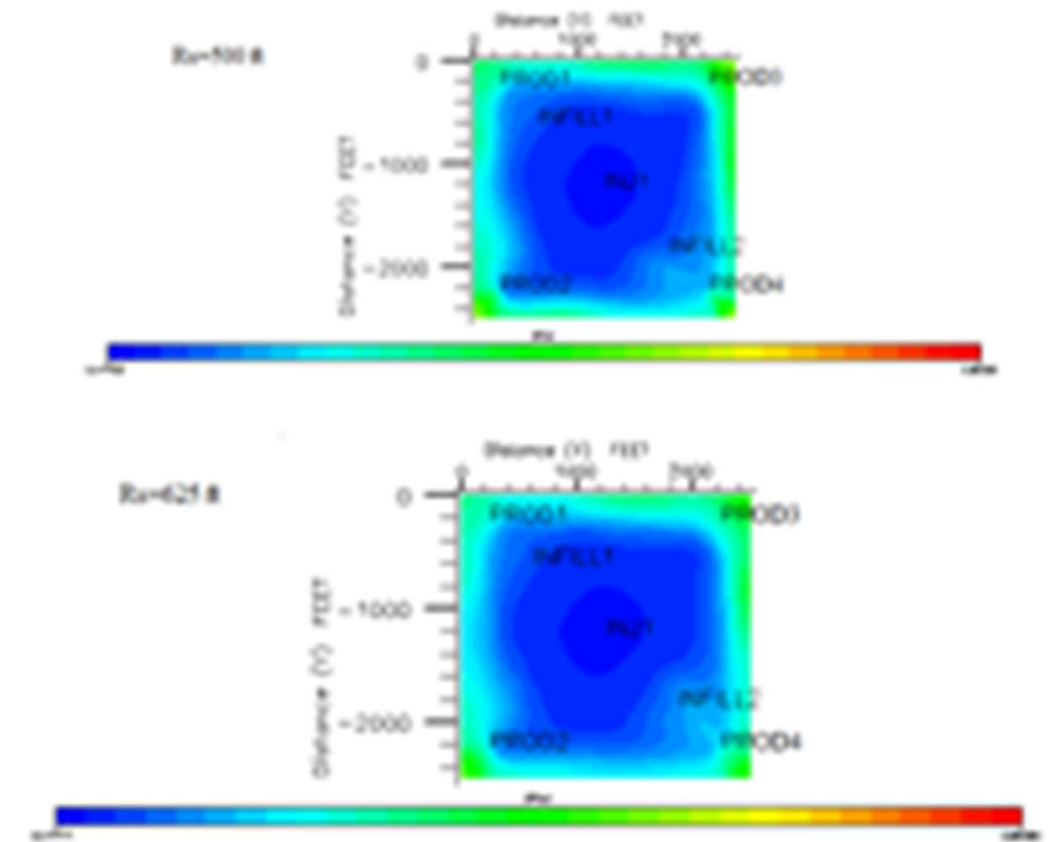

Ba atsa

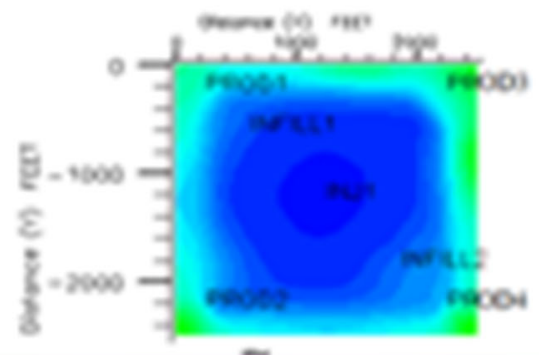


The results of this study can help engineers to better design appropriate infill drilling schemes.

Open Access This article is distributed under the terms of the Creative Commons Attribution 4.0 International License (http:// creativecommons.org/licenses/by/4.0/), which permits unrestricted use, distribution, and reproduction in any medium, provided you give appropriate credit to the original author(s) and the source, provide a link to the Creative Commons license, and indicate if changes were made.

\section{References}

Abukhamsin A (2009) Optimization of well design and location in real field. A report submitted to the department of energy resources engineering. Thesis of the Stanford University

Ariadji T et al (2014) A novel tool for designing well placements by combination of modified genetic algorithm and artificial neural networks. Petrol Sci Eng 122:69-82

Barber AH, George CJ, Stiles LH, Thompson BB (1983) Infill drilling to increase reserves-actual experience in nine fields in Texas, Oklahoma, and Illinois. SPE 11023

Cheng Y, McVay DA, Wang J, Ayers WB (2008) Simulation-based technology for rapid assessment of redevelopment potential in marginal gas fields-technology advances and validation in garden plains field, Western Canada sedimentary basin. SPE 100583:521-534

Driscoll VJ (1974) Recovery optimization through infill drillingconcepts, analysis, and field results. In: Paper SPE 4977 presented at the 49th annual meeting of the society of petroleum engineers of AIME, Houston, Texas, 6-9 October

French RL, Brimhall RM, Wu CH (1991) A statistical and economic analysis of incremental waterflood infill drilling recoveries in West Texas carbonate reservoirs. In: SPE 22624 presented at the SPE annual technical conference and exhibition, Dallas, 6-9 October

Fuller SM, Sarem AM, Gould TL (1992) Screening waterfloods for infill drilling opportunities. In: SPE 22333 presented at the SPE international meeting on petroleum engineering held in Beijing, China, 24-27 March

Gao H, McVay DA (2004) Gas infill well selection using rapid inversion methods. In: Paper SPE 55563, presented at the SPE annual technical conference and exhibition held in Houston, TX, 26-29 September

Gould TL, Munoz MA (1982) An analysis of infill drilling. In: SPE 11021 , presented at the 57th annual fall technical conference and exhibition of the society of petroleum engineers of AIME, New Orleans, Louisiana, pp 26-29

Gould TL, Sarem AM (1989) Infill drilling for incremental recovery. SPE 18941:229-237

Guan L, Du Y, Wang Z (2005) Petroleum lessons in past 20 years, World Petroleum Congress, WPC-18-0885

Holm LW et al (1980) Infill drilling vs. tertiary oil recovery vs. more imports. In: SPE 9094, presented at the SPE annual technical conference, Union Oil Co. of California
Hou J, Zhang SH (2007) A streamline-based model for potentially prediction of enhance oil recovery, SPE 105246

Hudson JW, Jochen JE, Jochen VA (2000) Practical technique to identify infill potential in low-permeability gas reservoirs applied to the milk river formation in Canada. In: SPE 59779, presented at the SPE/CERI gas symposium, Calgary, 3-5 April

Hudson JW, Jochen JE, Spivey JP (2001) Practical methods to highgrade infill opportunities applied to the mesaverde, morrow, and cotton valley formations. In: SPE 68598 presented at the SPE hydrocarbon economics and evaluation symposium, Dallas, 2-3 April

Isebor O, Durlofsky L, Ciaurri DE (2014) A derivative-free methodology with local and global search for the constrained joint optimization of well locations and controls. Comput Geosci 18:463-482

Malik ZA, Silva BA, Brimhall RM, Wu CH (1993) An integrated approach to characterize low permeability reservoirs connectivity to optimize waterflood infill drilling. In: SPE 25853 presented at the joint rocky mountain regional and low permeability reservoirs symposium, Denver, April 26-28

McCain WD Jr., Voneiff GW, Hunt ER, Semmelbeck ME (1993) A tight gas field study: Carthage (Cotton Valley) field. In: Paper SPE 26141 presented at the SPE gas technology symposium, Calgary, 28-30 June

Moyner O, Krogstad S, Lie K (2014) The application of flow diagnostics for reservoir management. SPE 171557, pp 306-323

Nasrabadi H et al (2012) Well placement optimization: a survey with special focus on application for gas/gas-condensate reservoirs. In: Presented at natural gas science and engineering, pp 6-16

Onswnulu JE, Durlofski LJ (2010) Application of particle swarm optimization algorithm for determining optimum well location and type. Comput Geosci 140:183-198

Sayyafzadeh M, Pourafshari P (2010) Increasing ultimate oil recovery by infill drilling and converting weak production wells to injection wells using streamline simulation. In: SPE132125-MS, Presented as conference paper in international oil and gas conference and exhibition in China, 8-10 June, Beijing, China

Shook G, Mitchell K (2009) A robust measure of heterogeneity for ranking earth models: the F-Phi curve and dynamic Lorenz coefficient. In: SPE annual technical conference and exhibition

Soto BR, Wu CH, Buleba AM (1999) Infill drilling recovery models for carbonate reservoirs-a multiple statistical, non-parametric regression, and neural network approach. In: SPE 57458, presented at the SPE eastern regional conference and exhibition, Charleston, West Virginia

Thakur GC, Satter A (1998) Integrated waterflood asset management. Tulsa, Okla, PennWell Book

Voneiff GW, Cipolla CA (1996) New approach to large-scale infill evaluations applied to the Ozona (Canyon) gas field. In: SPE 35203, presented at the SPE Permian oil and gas recovery conference. Midland, Texas

Wu CH et al (1989) An evaluation of waterflood infill drilling in west texas Clearfork and San Andres carbonate reserves. In: SPE 19783, presented at the SPE annual technical conference and exhibition, San Antonio, 8-11 October 